\title{
Return Period for Urban Rainwater Drainage Networks Based on the Lowest Total Social Investment Method: A Case Study in Tianjin, China
}

\author{
Yanjuan Yang, Mingcai Li*, Mingming Xiong, Jingfu Cao \\ Tianjin Climate Center, Tianjin, China
}

Received: 11 July 2018

Accepted: 21 October 2018

\begin{abstract}
Waterlogging is related to rainfall intensity as well as drainage network design. In previous studies, rainfall intensity was dominantly considered, while the design return period with the lowest total social investment of drainage networks was generally neglected. In this study, Guangkai Street in Tianjin in northern China was selected as a case study to determine the optimal design return period of drainage networks. According to the drainage networks for different design return periods, the depth of waterlogging was simulated based on the FloodArea model under the conditions of the rainfall exceeding the design return period. Furthermore, traffic losses due to waterlogging were determined by using the traffic loss model. When the sum of traffic losses and drainage network investment is smallest (i.e., the lowest total social investment), the corresponding return period is considered as the optimal design return period of drainage networks. By comparing the simulated depths of waterlogging and observations of 17 waterlogging monitoring points, we found that the FloodArea model has efficient simulation in most areas. Accordingly, the FloodArea model was used to simulate the depths of waterlogging with different return periods in Guangkai Street. The results show that the total social investment, including traffic losses and initial investment of drainage networks, is the lowest with the return period of the drainage networks in the selected area being designed as 5 years. This suggests that the design return period of the drainage networks in Guangkai Street should be upgraded to 5 years. The approach in this study is based on high-precision simulation (1 m GIS data) and actual waterlogging depth to ensure the accuracy of simulation. The optimal design return period is calculated in combination with traffic losses and initial investment of drainage networks, providing reference for the design of drainage networks in specific areas.
\end{abstract}

Keywords: climate change, drainage networks, total social investment, return period, urban waterlogging

*e-mail: mingcaili_qhzx@163.com 


\section{Introduction}

Under the conditions of global warming, extreme rainfall events have been increasing in many areas with geographical heterogeneity [1-5]. Even in some areas where annual mean precipitation generally decreases slightly, extreme rainfall events still increase significantly [6]. Extreme rainfall events, to a large extent, trigger urban waterlogging and floods, especially in low-lying coastal areas. This causes not only property damage but also human casualties [7].

The runoff coefficients in large cities become high with the gradual increase in impervious pavements. If the drainage capacity is low, heavy rains can easily result in waterlogging. In recent years, extreme rainfall events have been frequent in China, resulting in urban waterlogging in many cities. For example, what's referred to locally as the "July 21 Rainstorm" in Beijing [8] and the "July 18 Rainstorm" in Ji'nan [9] caused great loss to life and property as well as a negative impact on traffic safety. However, some cities still have the risk of waterlogging even under non-extreme heavy rainfall conditions, simply due to the inadequate drainage capacity. For example, from 17:00 to 20:00 on July 19, 2015, the rainfall in Tianjin was only $20 \mathrm{~mm}$, which did not reach a return period of 1 year, but the rainfall caused waterlogging in several road segments. The depth of waterlogging in some segments exceeded $30 \mathrm{~cm}$, greatly affecting city traffic. The occurrence and characteristics of extreme rainfall events and resulting urban waterlogging have therefore caused concern among researchers and policymakers in recent years. Thus, previous studies have focused on the influential factors and the formation mechanism of urban waterlogging [10-12]. However, studies on the design of drainage networks in large cities under the background of extreme rainfall events are very limited.

In the planning and design of urban rainwater drainage networks, the design return period is usually settled based on rainstorm intensity, i.e., the intensityduration-frequency curve. Generally, drainage networks with a high design return period have a stronger drainage capacity, but the construction cost will inevitably be much higher. In contrast, a lower design return period decreases the construction cost, but the drainage capacity will be significantly reduced and the risk of waterlogging disasters will increase [13]. In the design of drainage networks under the conditions of climate change, there is an urgent problem to be solved: that of how to choose a design return period to achieve the optimal balance between the investment of drainage networks and the risk of urban waterlogging. Some researchers introduced the concept of total social investment, which is the sum of the initial investment in constructing drainage networks and future losses that might be caused by urban waterlogging [1314]. From the perspective of economics, a minimal total social investment is necessary to optimize the drainage networks. In this study, Tianjin, a large city in northern China, is taken as an example. Guangkai Street in Nankai District, with a dense population, was selected because of the extreme sensitivity of drainage networks to rainfall due to the relatively lower design return period. The Tianjin government has planned to add pump stations but does not know exactly how to establish new rainwater pipes due to a lack of scientific basis and criteria for reconstruction. The project investment for drainage networks at different design return periods and corresponding traffic losses were calculated. The optimal design return period of drainage networks was determined by the method of lowest total social investment. This study will provide a scientific basis for the design of drainage networks.

\section{Material and Methods}

\section{Study Area}

Tianjin is the second largest city by urban population in northern China, following Beijing (Fig. 1, $\left.39^{\circ} 10^{\prime} \mathrm{N}, 117^{\circ} 10^{\prime} \mathrm{E}\right)$. With a population of approximately 10 million spread across $11,919 \mathrm{~km}^{2}$, Tianjin is located at the lower reaches of the Haihe River and is adjacent to the Bohai Sea. Tianjin has a semi-humid continental monsoon climate with monsoon prevailing all year round and four distinct seasons. The annual precipitation in Tianjin is $525 \mathrm{~mm}$, most of which occurs from June to August. The mean annual temperature is $13.5^{\circ} \mathrm{C}$, with annual extremes of $41.7^{\circ} \mathrm{C}$ and $-23.3^{\circ} \mathrm{C}$. In the present study, Guangkai Street is taken as a case study for severe waterlogging. Guangkai Street is located at north-central Nankai District, stretching from Nankai Fifth Road in the east to Jinhe River in the west, and from Changjiang Road in the south to Xiguan Avenue in the north. Guangkai Street covers a surface area of $1.7 \mathrm{~km}^{2}$, with 27,015 households and 76,549 inhabitants. Guangkai Street consists of 13 communities, with some areas low-lying and at high risk of urban waterlogging. Waterlogging-prone points in Guangkai Street are mainly distributed in Nanguangkai Fifth Road, Qinghuaci Street, Guangkai Fourth Road, Guangkai Second Road, Tianbao Road, Nankai Sixth Road, Huajiachang Street, the intersection of the South Road and Yongji Garden, the intersection of the South Road and Fuxinzhuan, and the intersection of Guangkai Sixth Road and Tianbao Road.

\section{Calculating Precipitation in Different Return Periods}

The intensity-duration-frequency curve is the basis for drainage networks planning and design [15]. Precipitation in different return periods is calculated by Tianjin's intensity-duration-frequency curve Eq (1), which is calculated by the methods proposed in CDOWE [16] and TGEIDFCDRP [17], and based on the minute-by-minute rainfall data of Tianjin Urban Climate 


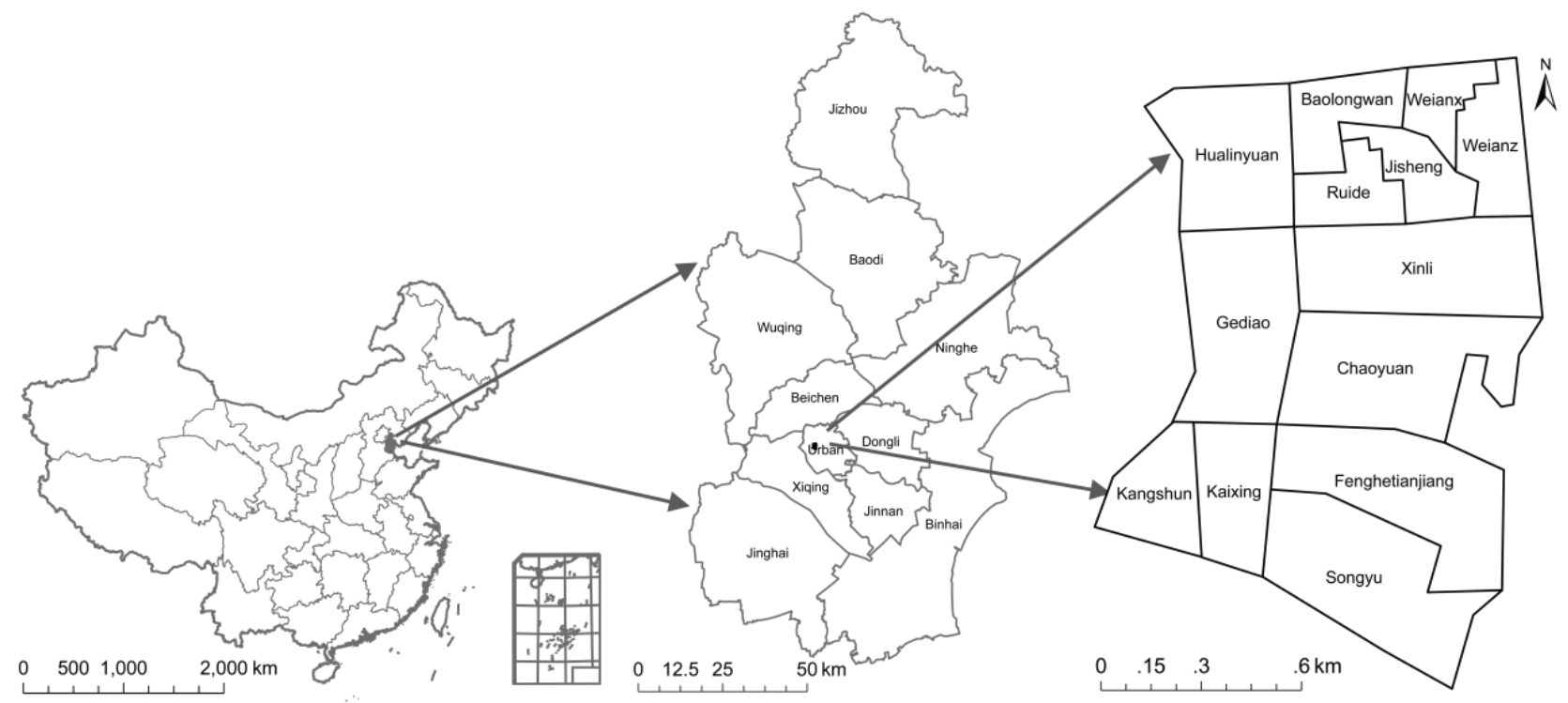

Fig. 1. Location of study area.

Observation Station during 1987-2016. Precipitation in different return periods were calculated as:

$$
q=\frac{1791.542 \times(1+0.997 \lg P)}{(t+9.552)^{0.714}}
$$

In Eq (1), $q$ is precipitation intensity, and $t$ and $P$ are precipitation duration and the return period, respectively.

\section{Waterlogging Simulation}

The simulation of waterlogging is carried out by the FloodArea model. FloodArea model, as a hydrological model for flood risk analysis, has been receiving more attention during recent years [18]. The model developed by the German company Geomer efficiently enables users to simulate mountain torrent and urban waterlogging triggered by rainstorms [1819]. As a distributed hydrodynamic model, FloodArea is based on fluid mechanics principles combined with GIS technology. During the process of waterlogging simulation in this study, the influences of underlying surface, elevation, and other factors are considered [18]. In this study, the calculation of waterlogging area is based on the hydrodynamic approach, and all eight neighbors of a raster cell were considered [20]. The discharge volume to the neighboring cells is calculated using the Manning-Strickler formula and the value of roughness in this formula can be found in Xue et al. [18]. The direction of water flow can be obtained by the slope of the terrain, and flow depth was determined by the difference between water level and maximum terrain elevation along the flow path [20]. FloodArea model provides 3 methods, i.e. water level, hydrograph and rainstorm, to simulate the runoff generation process. Rainstorm was selected to simulate waterlogging at
Guangkai Street. Meanwhile, geographic information data with a resolution ratio of $1 \mathrm{~m}$ was adopted for accurately identifying and simulating waterlogging in Guangkai Street.

\section{Calculating Traffic Loss}

The rainstorm-triggered waterlogging usually has a direct impact on traffic. The economic losses due to waterlogging could be calculated by the depthdamage curve [13, 21-22]. However, the depth-damage curve requires a great amount of disaster data as support. It is difficult to obtain the data for most areas. Therefore, the traffic losses in this study are expressed by a generalized model. The advantage of the model is that more comprehensive traffic losses can be made independent from a large amount of disaster data. The traffic losses caused by waterlogging are defined as fuel consumption as a result of decreasing vehicle speed and the time value losses due to traffic jam or delay [14, 23].

$$
Z=Z_{1}+Z_{2}
$$

...where $Z$ represents the waterlogging-caused traffic losses (RMB); and $Z_{1}$ and $Z_{2}$ represent the fuel consumption (RMB) and the time value cost (RMB), respectively.

\section{Calculating Fuel Consumption Economic Loss}

The fuel consumption economic loss model considers the normal traffic flow as the benchmark (supposing that the traffic is normal under the weather conditions without extreme rainfall events). The model of vehicle speed decreasing in line with the depth of waterlogging is shown in formula 3 [14]. 


$$
v=\frac{v_{0}}{2} \tanh \left(\frac{-x+a}{b}\right)+\frac{v_{0}}{2}
$$

...where $v$ is the vehicle speed $(\mathrm{km} / \mathrm{h})$ and $v_{0}$ is the design speed $(\mathrm{km} / \mathrm{h})$, i.e., the varying values for different types of roads; $x$ is the depth of waterlogging $(\mathrm{cm}) ; a$ is the half of the critical water depth value stopping the vehicles (cm); and $b$ is the elastic attenuation coefficient, representing the decreasing rate of the vehicle speed with the depth of waterlogging (generally in the range of 3 to 5). A smaller value of $b$ indicates quicker speed attenuation. Generally, the curbs of urban roads are designed at $15 \mathrm{~cm}$ in height. Therefore, drivers have difficulty identifying lane edges when the depth of waterlogging exceeds $15 \mathrm{~cm}$. Above $15 \mathrm{~cm}$, vehicle speeds will be close to zero and traffic will stop. As a result, the depth of waterlogging for this model is in the range of 0 to $15 \mathrm{~cm}$.

Fuel consumption economic losses are calculated by the relationship of vehicle speed to fuel consumption. According to the mechanical theory of vehicles, fuel consumption economic losses are obtained as [14]:

$$
Z_{1}=\sum_{i=1}^{c}\left[\frac{p_{e} b_{e} a}{71} n\left(\frac{1}{v}-\frac{1}{v_{b}}\right) \frac{l_{i}}{100}\right]
$$

In Eq (4), $p_{e}$ is engine power (71 kW) and $b_{e}$ is the effective fuel consumption (150 g / (KW·h)); $c$ is the amount of waterlogged segments; $a$ is the gasoline unit price (RMB 6.6 Yuan /L); $\mathrm{n}$ is the traffic volume influenced by waterlogging; $v_{e}$ is the critical speed of minimum oil consumption $(80 \mathrm{~km} / \mathrm{h})$; and $l_{i}$ is the length of a specific waterlogged segment $(\mathrm{km})$.

\section{Calculating Time Value Loss}

The GDP per capita is used to measure the economic losses of time value. The model is defined as follows [14]:

$$
\begin{gathered}
Z_{2}=M_{1}+M_{2} \\
M_{1}=\sum_{i=1}^{c} n \varphi \Delta t \beta m_{1} \\
M_{2}=\sum_{i=1}^{c} n(1-\varphi) \Delta t \beta m_{2} \\
\Delta t=\frac{l_{i}}{v}-\frac{l_{i}}{v_{0}}
\end{gathered}
$$

In Eqs (5-8), $M_{1}$ is the time value loss for cars (RMB); $M_{2}$ is the time value loss for buses (RMB); $\varphi$ is the proportion of cars in the vehicles; $\Delta t$ is lost time (h); and $\beta$ is the time value index $(\mathrm{RMB} / \mathrm{h})$. The GDP per capita in Tianjin of 2011 is used as the benchmark. It is assumed that the annual average GDP growth in the next 50 years will remain the same as that during 2001 to 2010 , i.e., $12.2 \%$. According to this, the GDP per capita in the upcoming 50 years will be RMB 35.6 Yuan $/ \mathrm{h} /$ person.); $m_{1}$ and $m_{2}$ are the average passenger numbers of a car (1.5-2) and a bus (40-80), respectively.

$$
\begin{aligned}
& Z=\sum_{i=1}^{c}\left\{n \sum _ { i = 0 } ^ { a } \left[\frac{p_{e} b_{e} a}{71}\left[\frac{2}{v_{0}\left[\tanh \left(\frac{-x+a}{b}\right)+1\right]}-\frac{1}{v_{b}}\right] \cdot \frac{l_{i}}{100}+\right.\right. \\
& \left.\left.+\frac{l_{i}}{v_{0}}\left[\frac{2}{\tanh \left(\frac{-x+a}{b}\right)+1}-1\right] \cdot \beta\left[\varphi m_{1}+(1-\varphi) m_{2}\right]\right]\right\}
\end{aligned}
$$

By substituting the equations above into Eqn2, the traffic loss model is obtained as follows [14]:"

\section{Calculating Total Loss}

According to the loss from a single rainfall event with different frequencies and the number of possible occurrences, the total loss as a result of excessive rainfall in the service life of the drainage networks could be obtained for drainage networks (the maximum return period of rainfall is considered as 50 years) [14].

$$
S=\sum_{i=1}^{n} S_{i} P_{i} \quad(i=1,2,3,5,10,20,30,50)
$$

...where $S$ is the total loss as a result of excessive rainfall events in the service life of the drainage networks; $S_{i}$ is the loss from single rainfall at an return period; and $P_{i}$ is time of rainfall at different return periods within 50 years.

\section{Results and Discussion}

\section{Waterlogging Simulation Evaluation}

The maximum depth of waterlogging is simulated and then the simulation efficiency is evaluated based on the simulation of rainfall events on August 30-31, 2014 (Fig. 2). A total of 17 waterlogging monitoring points have been established in Guangkai Street. By comparing the simulation and observation values, it is found that there are 12 monitoring points at the same waterlogging depth level, accounting for $70.6 \%$ of all waterlogging monitoring points. There is only 1 point with the simulation larger than the observation value, and 4 points have smaller simulation values compared 

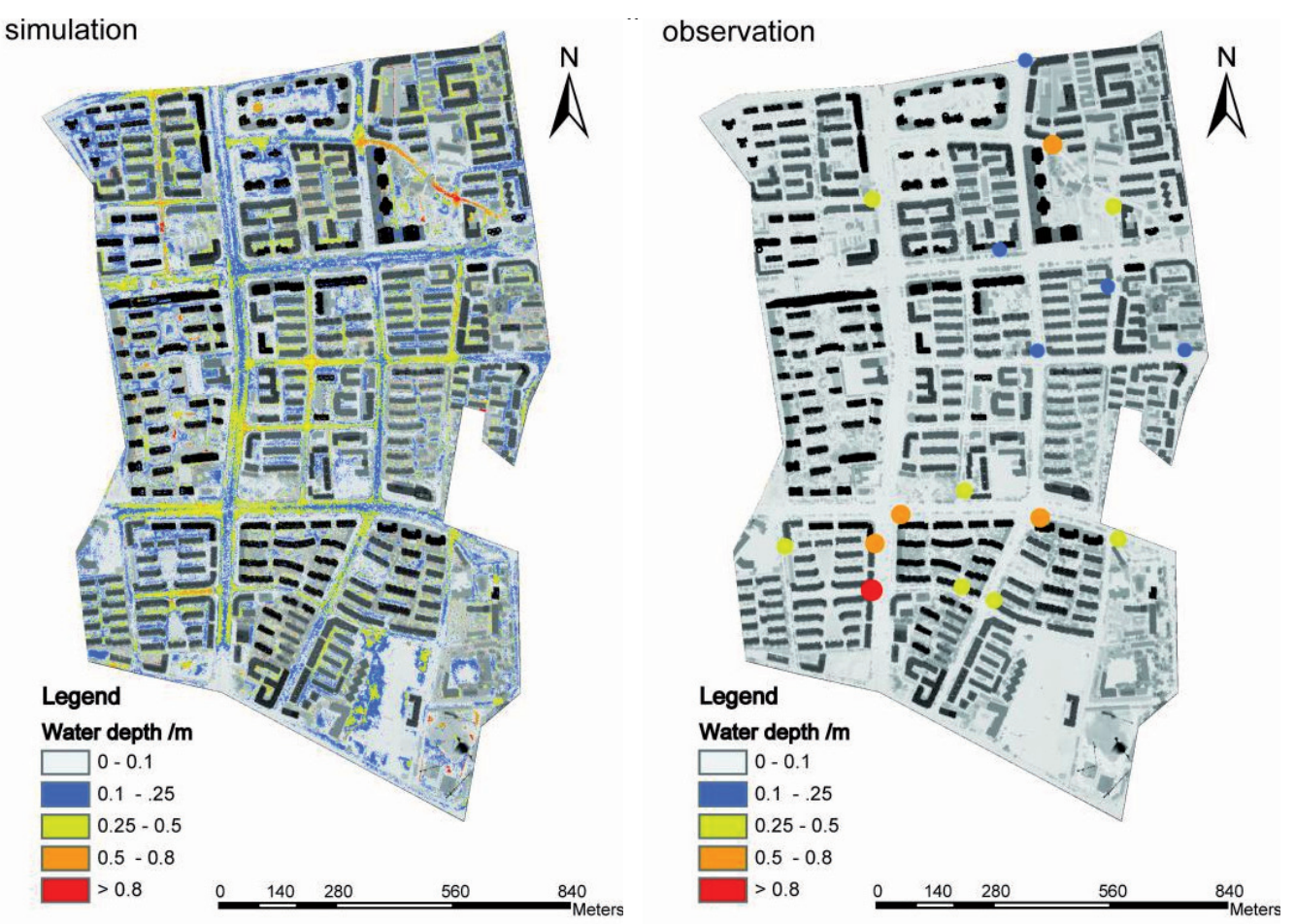

Fig. 2. Comparisons between the simulated and observed waterlogging depths.

with the observation values. These results suggest that FloodArea has efficient simulation in most areas, except in and around the Kaixing Apartment on southwest Guangkai Street, where the simulation value is relatively smaller. Accordingly, the FloodArea model is used to simulate the depths of waterlogging with different return periods in Guangkai Street.

According to our previous study, the rainfall durations in Tianjin are mostly within $3 \mathrm{~h}$, and the 3 h-rainfall processes are therefore selected for analysis [24]. Based on the intensity-duration-frequency curve, precipitation with $3 \mathrm{~h}$ duration in the return periods of $1,2,3,5,10,20,30$, and 50 years are calculated. The Chicago rainfall pattern (rainfall peak coefficient: 0.368 ) is used for time distribution. Rainfall generally presents a single peak distribution in Tianjin and most parts of northern China, and Chicago rainfall patterns can usually and efficiently be used to determine rainfall patterns within a single peak. In addition, the Chicago rainfall pattern is widely used in drainage design due to its simple calculation and good simulation effect [17]. The hourly precipitation obtained by the Chicago rainfall pattern is input into the FloodArea model as the initial precipitation. Accordingly, the depths of waterlogging at different return periods in Guangkai Street can be obtained.

\section{Design Return Period}

Due to the lack of detailed assessment, the investment of drainage networks refers to previous studies in other regions [14]. An overview of the drainage networks
Table 1. Drainage network investments in Guangkai Street.

\begin{tabular}{|c|c|c|c|c|c|}
\hline Return period (a) & 1 & 2 & 3 & 5 & 10 \\
\hline Investment $\left(\mathrm{RMB} \times 10^{6}\right)$ & 22.1 & 25.4 & 27.3 & 29.9 & 33.3 \\
\hline
\end{tabular}

investment in Guangkai Street at different design return periods $(1,2,3,5,10$ years) is shown in Table 1 . It is can be found that, with the increasing return periods, the project cost of drainage networks greatly increases in accordance.

Assuming that the service life of the drainage pipeline is 50 years, the times of rainfall are expected to be 50 with the return period of 1 year, and 25,17 , $10,5,2.5$ and 1 with the return periods of $2,3,5,10$, 20 , and 50 years, respectively. To verify the reliability of the results calculated by probability statistics, the times of rainfall events exceeding the standards of different return periods in the last 50 years from 1968 to 2017 in the Tianjin Urban Climate Observation Station are calculated and then compared with the calculated results by probability statistics (Table 2). It is found that the times calculated are close to the times of actual occurrences. Therefore, the calculated times of rainfall events are used to estimate the losses caused by waterlogging.

According to the depths of waterlogging simulated by the FloodArea model, ArcGIS technology is used for extracting the road lengths corresponding to different depths of waterlogging. The traffic losses caused by rainfall events exceeding the standards of different return periods of drainage networks are calculated on the basis of the traffic loss model. Fig. 3 shows that, 
Table 2. Comparisons between the times of calculated and actual rainfalls exceeding the standards of different return periods during 1968-2017.

\begin{tabular}{|c|c|c|c|c|c|}
\hline Return period (a) & 3 & 5 & 10 & 20 & 50 \\
\hline Actual times & 18 & 11 & 5 & 2 & 1 \\
\hline Calculated times & 17 & 10 & 5 & 2.5 & 1 \\
\hline
\end{tabular}

with the increase in the design return period of drainage networks, the flow capacity of the drainage networks correspondingly increases, waterlogging weakens, and traffic losses decrease accordingly. If the return period of drainage networks is designed as 10 years, the traffic losses caused by waterlogging will be only RMB 331,989.7. However, the 10-year return period of drainage networks will largely increase the construction cost of networks. By adding the drainage networks investments with different design return periods and the traffic losses caused by excessive rainfall events, the total social investment for different design return periods can be obtained (Fig. 3). It can be clearly found that the total social investment is lowest when the return period of the drainage networks is designed as 5 years. Therefore, a 5 -year design return period is the best in this area.

In this study, it is the first time to obtain the optimal design return period of drainage networks by simulating the waterlogging at a meter scale based on high resolution geographic information data. In the meter scale simulation, the waterlogging in the street can be easily and accurately obtained. Thus, traffic losses can be estimated more accurately. It is necessary to note that the losses caused by urban waterlogging are various, such as building damage in low-lying areas, property damage to homes, shut-down losses of construction site and some indirect losses. In this study, only traffic losses

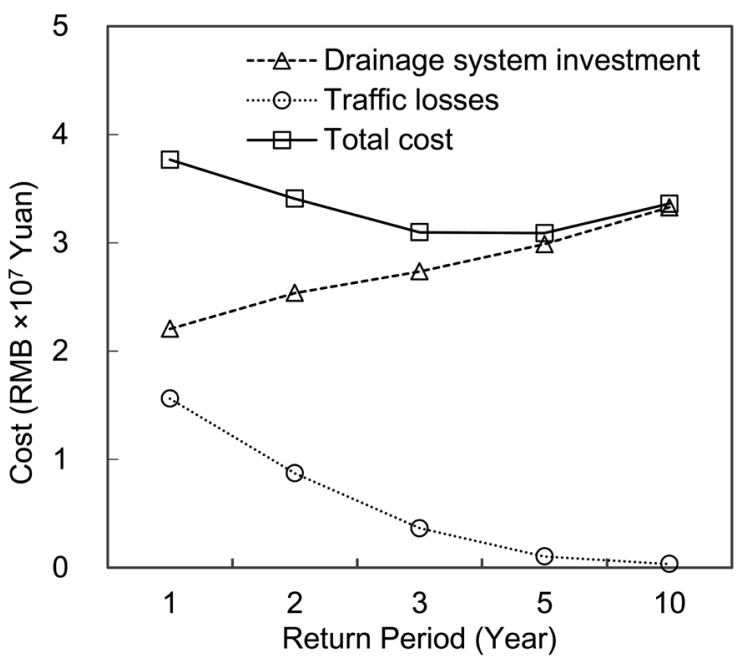

Fig. 3. Variations of the investment, traffic losses and total social investment of the drainage networks with different design return periods. are taken into account; other losses are not considered, which may cause some deviations in designing the return period. Losses in other industries due to urban waterlogging should be further studied in the future. In addition, the design and construction of drainage networks are based on past precipitation data. The CMIP5 models predict that the future extreme rainfall in northern China will increase, and the precipitation intensity will change accordingly [25-26]. This outcome will inevitably affect the design of drainage networks [27-28]. Therefore, further studies should be conducted on how to work out the drainage networks design criteria to match climate conditions in the future.

\section{Conclusions}

In this study, a new method for the optimal design return period of drainage networks is proposed by taking into account both the construction cost of drainage networks and the economic losses caused by urban waterlogging. Guangkai Street in Tianjin, which is a large city in the north of China, was taken as a case study in order to reveal the optimal design return period of drainage networks. The results suggest that the total social investment (i.e., the sum of traffic losses and initial investment of drainage networks) reaches the lowest value when the return period of drainage networks in Guangkai Street is designed as 5 years. At present, in most parts of Tianjin, the return periods are designed as 1 year for drainage networks and 3 years for tunnels and culverts. The low design standard has led to frequent urban waterlogging in recent years. This study suggests that the design return period of drainage networks for Guangkai Street and other areas in Tianjin should be upgraded to 5 years to cope with extreme rainfall events under the conditions of climate change.

\section{Acknowledgements}

This work was financially supported by the Basic and Frontier Technology Research Program Foundation of Tianjin (15JCYBJC22300) and the National Key R \& S program of China (2018YFA0606302).

\section{Conflict of Interest}

The authors declare no conflict of interest.

\section{References}

1. MICHAELS P.J., KNAPPENBERGER P.C., FRAUENFELD O.W., DAVIS R.E. Trends in precipitation on the wettest days of the year across the contiguous USA. International Journal of Climatology, 24 (15), 1873, 2004. 
2. ROY S.S., ROBERT C., BALLING J.R. Trends in extreme daily precipitation indices in India. International Journal of Climatology, 24 (4), 457, 2004.

3. JUNG I.W., BAE D.H., KIM G. Recent trends of mean and extreme precipitation in Korea. International Journal of Climatology, 31 (3), 359, 2011.

4. CHOI W., TAREGHIAN R., CHOI J., HWANG C. Geographically heterogeneous temporal trends of extreme precipitation in Wisconsin, USA during 1950-2006. International Journal of Climatology, 34 (9), 2841, 2014.

5. SUPARI S., TANGANG F., JUNENG L., ALDRIAN E. Observed changes in extreme temperature and precipitation over Indonesia. International Journal of Climatology, 37 (4), 1979, 2017.

6. WU Y.J., WU S.Y., WEN J.H., XU M., TAN J.G. Changing characteristics of precipitation in China during 1960-2012. International Journal of Climatology, 36 (3), 1387, 2016.

7. VILLARINI G., SMITH J.A., BAECK M.L., STURDEVANT-REES P., KRAJEWSKI W.F. Radar analyses of extreme rainfall and flooding in urban drainage basins. Journal of Hydrology, 381 (3), 266, 2010.

8. SUN J.H., ZHAO S.X., FU S.M., WANG H.J., ZHENG L.L. Multi-scale characteristics of record heavy rainfall over Beijing area on July 21, 2012. Chinese Journal of Atmospheric Sciences, 37 (3), 705, 2013 [In Chinese].

9. LIU H.R., LI C.Y. Impacts of the dry intrusion on Ji'nan torrential rain occurring on 18 July 2007. Chinese Journal of Atmospheric Sciences, 34 (2), 374, 2010 [In Chinese].

10. LI D.M., ZHANG H.P., LI B.F. Basic theory and mathematical modeling of urban rainstorm water logging. Journal of Hydrodynamics (Ser. B), 1, 17, 2004.

11. XIE Y.Y., HAN S.Q., YOU L.H., WANG Y., YAN C.L. Risk analysis of urban rainfall waterlogging in Tianjin City. Scientia meteorologica Sinica, 24 (3), 342, 2004 [In Chinese].

12. SU M.R., ZHENG Y., HAO Y., CHEN Q.H., CHEN S.H., CHEN Z.Y., XIE H. The influence of landscape pattern on the risk of urban water-logging and flood disaster. Ecological Indicators, 92, 133, 2018.

13. FORTUNATO A., OLIVERI E., MAZZOLA M.R. Selection of the optimal design rainfall return period of urban drainage systems. Procedia Engineering, 89 (2004), 742, 2014.

14. WU M.Z., XU S.R. Study on design return period of rainwater system in Changsha based on lowest social total investment. Water Resources and Power, 34 (1), 98, 2016 [In Chinese].
15. PECK A., PRODANOVIC P., SIMONOVIC S.P.P. Rainfall intensity Duration Frequency Curves under climate change: city of London, Ontario, Canada. Canadian Water Resources Journal, 37 (3), 177, 2012.

16. CDOWE. Code for design of outdoor wastewater engineering. 2014 [In Chinese].

17. TGEIDFCDRP. Technical guidelines for establishment of Intensity-Duration-Frequency Curve and design rainstorm profile. 2014 [In Chinese].

18. XUE F.C., HUANG M.M., WANG W., ZOU L. Numerical simulation of urban waterlogging based on FloodArea model. Advances in Meteorology, 2016 (1), 1, 2016.

19. TYRNA B., ASSMANN A., FRITSCH K., JOHANN G. Large scale high resolution pluvial flood hazard mapping using the raster-based hydrodynamic 2D model FloodAreaHPC. Journal of Flood Risk Management, 11 (S2), S1024, 2018.

20. FloodArea and FloodArea ${ }^{\mathrm{HPC}}$ - ArcGIS - extension for calculating flooded areas (User Manual Floodarea10.0), 2011.

21. OLIVERI E., SANTORO M. Estimation of urban structural flood damages: the case study of Palermo. Urban Water, 2 (3), 223, 2000.

22. FRENI G., LA L.G., NOTARO V. Uncertainty in urban flood damage assessment due to urban drainage modelling and depth-damage curve estimation. Water Science and Technology, 61 (12), 2979, 2010.

23. DU L., YANG X.K. An Exploration of influence of accumulated rainwater on urban traffic. 11th International Conference of Chinese Transportation Professionals, 187, 2011.

24. XIONG M.M., XU S., LI M.C., YANG Y.J., REN Y., CAO J.F. Characteristics of hourly precipitation in Tianjin. Torrential Rain and Disasters, 35 (1), 84, 2016 [In Chinese].

25. ZHOU B.T., WEN Q.H., XU Y., SONG L.C., ZHANG $X . B$. Projected changes in temperature and precipitation extremes in China by the CMIP5 multimodel ensembles. Journal of Climate, 27 (17), 6591, 2014.

26. CHEN H.P., SUN J.Q., LI H.X. Future changes in precipitation extremes over China using the NEX-GDDP high-resolution daily downscaled data-set. Atmospheric and Oceanic Science Letters, 10 (6), 403, 2017.

27. MADSEN H., ARNBJERG-NIELSEN K., MIKKELSEN P.S. Update of regional Intensity-Duration-Frequency Curves in Denmark: tendency towards increased storm intensities. Atmospheric Research, 92 (3), 343, 2009.

28. WILLEMS P. Revision of urban drainage design rules after assessment of climate change impacts on precipitation extremes at Uccle, Belgium. Journal of Hydrology, 496(4), 166, 2013. 